\title{
PENURUNAN KADAR RHODAMIN B DALAM AIR LIMBAH DENGAN BIOFILTRASI SISTEM TANAMAN
}

\author{
K. Yogi Purnamawati ${ }^{1 *}$, IW.Budiarsa Suyasa ${ }^{1)}$, IG. Mahardika ${ }^{2)}$ \\ 1)Program Studi Ilmu Lingkungan PPs Universitas Udayana, Denpasar \\ ${ }^{2)}$ Fakultas Peternakan Universitas Udayana, Denpasar \\ *Email : yogie_purnamawati@yahoo.com
}

\begin{abstract}
The textile industry is growing rapidly and as the result it's producing waste that can harm the environment. One of which is rhodamine B. Rhodamine B is a synthetics dyes that have a form crystalline which an organic base containing amino groups, so it is difficult to degrade naturally by microorganism. Biofiltration system method is one of many ways in handling wastewater. Layered filtration unit of sand and rocks combine with the adsorption of plant and decomposition by microorganisms in rhizosphere so that wastewater can be reused. The aim of this study determined effectiveness and capacity of biofiltration system vegetation in reducing concentrate of rhodamine-B, total dissolved solid (TDS), total suspended solid (TSS) and the $\mathrm{pH}$ in wastewater.

The result showed that biofiltration effectiveness in reducing rhodamine B, TDS and TSS concetrate were $51,70 \% ; 47,60 \% ; 50,44 \%$ while decreasing and stabilization of $\mathrm{pH}$ obtained at 30 hours treatment time with $\mathrm{pH}$ value is 7,5 . Capacity of biofiltration system vegetation with volume $0,06 \mathrm{~m}^{3}$ can reduced rhodamine B, TDS and TSS by 0,2256 ppm; 278,0237 ppm and 9,4978 ppm respectively, while the optimum detention time of wastewater in the biosystem for reducing rhodamine B was 30 hours and for TSS and TDS was 36 hours. It can be concluded that biofiltration system vegetation was able to reduce rhodamine B, TDS, TSS and $\mathrm{pH}$ of wastewater.
\end{abstract}

Keywords: Biofiltration System Vegetation; Rhodamine B; Effectiveness; Capacity

\section{PENDAHULUAN}

Rhodamin B adalah zat warna sintetik berbentuk serbuk, mengandung gugus amino yang bersifat basa dan inti benzen, sehingga rhodamin B termasuk senyawa yang sulit didegradasi oleh mikroorganisme secara alami. Zat warna rhodamin B banyak digunakan oleh industri tekstil. Masuknya zat warna rhodamin B dalam perairan akan mempengaruhi $\mathrm{pH}$ air lingkungan yang menyebabkan terganggunya mikroorganisme dan hewan air (Laksono, 2009). Rhodamin B dalam tubuh manusia dapat menimbulkan masalah serius karena dapat menyebabkan iritasi saluran pernafasan, iritasi kulit, iritasi pada mata, iritasi pada saluran pencernaan, keracunan dan kanker hati (Trestiati, 2003).

Perkembangan dunia perindustrian di Indonesia terutama industri tekstil di Indonesia semakin meningkat. Dari data yang diperoleh Kementerian Perindustrian Republik Indonesia, usaha tekstil pada tahun 2011 mengalami kenaikan sebesar 7,51\% (Kemenperin, 2011). Industri tekstil di Bali adalah salah satu sektor non migas yang menyumbang devisa terbesar. Menurut penelitian Sari (2013) Jumlah perusahaan garmen di Kota Denpasar 157 buah dan yang tergabung dalam e-commerce sebanyak 44 buah. Ironisnya berkembangnya industri tekstil tidak sebanding dengan pengelohan limbah yang dihasilkan. Sangat jarang yang memperhatikan dan mengolah limbah yangdihasilkan sebelum dibuang ke lingkungan. Untuk mencegah timbulnya pencemaran lingkungan dan bahaya terhadap kesehatan manusia serta makhluk hidup lainnya, limbah bahan berbahaya dan beracun harus dikelola secara khusus agar dapat dihilangkan atau dikurangi sifat bahayanya.

Salah satu alternatif penanganan limbah adalah dengan teknik biofiltrasi. Teknik ini memanfaatkan kemampuan aktifitas mikroba mendegradasi/ mengeliminasi senyawa polutan. Untuk memberikan alternatif pengolahan limbah pencelupan kain yang higenis, unit pengolahan filtrasi berlapis dari pasir danbebatuan yang dipadukan dengan penyerapantanaman maupun perombakan mikroba pada risosfirakar akan memberikan hasil efektif bagi pemanfaatankembali air limbah. Aplikasi metode biofiltasi telah banyak dilaporkan khususnya dalam pengolahan limbah cair, seperti limbah cair industri tahu, limbah pabrik alkohol (Husin, 2008; Suwarno, 2003). Menurut Rittmann dan McCarty (2001), biofiltrasi juga dapat diaplikasikan dalam pengolahan limbah cair bahan-bahan kimia, domestik, bahan makanan, soft drink, landfill leachate dan industri farmasi. Hasil penelitian Suyasa dan Dwijani (2007) menyatakan bahwa, pengolahan limbah dengan biosistem menggunakan saringan pasir-tanaman mampu menurunkan nilai 
BOD sebesar 93,63\% dan CODsebesar 56,50 \% pada limbah pencelupan.

Adopsi dari beberapa hasil penelitian tersebut tentunya dapat dicobakan untuk menurunkan kadar rhodamin B yang biasanya terdapat pada limbah tekstil. Pemanfaatan teknik biofiltrasi sistem tanaman pada penelitian ini bertujuan untuk mengetahui efektivitas dan kapasitas biofiltrasi sistem tanaman dalam menurunkan kadar rhodamin B, Total Dissolved Solid (TDS), Total Suspended Solid (TSS) dan derajat keasaman $(\mathrm{pH})$ pada air limbah.

\section{METODE PENELITIAN}

\subsection{Tempat dan Waktu Penelitian}

Penelitian dilakukan di Laboratorium Kimia Lingkungan Jurusan Kimia FMIPA Unud, Laboratorium UPT Analitik Unud dan Laboratorium Bersama FMIPA Unud Kampus Bukit Jimbaran.Waktu penelitian keseluruhan termasuk persiapan membutuhkan waktu 4 bulan yaitu dari bulan September 2014 - Januari 2015.

\subsection{Alat dan Bahan Penelitian}

Bahan-bahan yang diperlukan dalam penelitian ini adalah sampel tanah sebagai sumber bibit yang akan diambil dari selokan disekitar limbah pencelupan yang berlokasi di Denpasar Selatan. Tanaman yang akan dibibit Ipomoea crassicaucalis serta media campuran pasir dan koral. Beberapa bahan kimia utama yaitu rhodamin B, glukosa $(\mathrm{KH})$, $\mathrm{K}_{2} \mathrm{HPO}_{4}, \mathrm{KH}_{2} \mathrm{PO}_{4},\left(\mathrm{NH}_{4}\right)_{2}\left[\mathrm{Fe}\left(\mathrm{SO}_{4}\right)_{2}\right] \cdot 6 \mathrm{H}_{2} \mathrm{O}, \mathrm{MgSO}_{4}$, $\mathrm{FeSO}_{4}$, ekstrak ragi, $\mathrm{H}_{2} \mathrm{SO}_{4} \mathrm{~s}$, aquades dan kertas saring wathman.Alat-alat yang diperlukan dalam penelitian ini antara lain : peralatan gelas untuk pembibitan, kotak kaca untuk media tanaman, pipa dan saluran sampling. Pipet volume, pH meter, alatalat gelas, timbangan analitik, desikator, oven dan spektrofotometer uv vis.

Untuk konstruksi unitrhizoekosistem pada lahan basah berupa unit pengolahan terdiri dari sebuah tempat semaian ukuran $125 \mathrm{~cm}$ x $58 \mathrm{~cm}$ x 36 cm dan dilengkapi dengan tabung tempat pengambilan sampel. Bak perlakuan diisi dengan batu koral ukuran $5 \mathrm{~cm}$ setinggi $10 \mathrm{~cm}$ kemudian diatasnya diisi campuran pasir dan sedikit koral

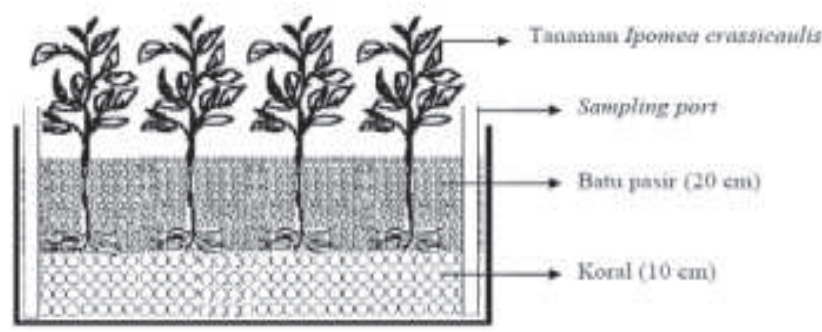

Gambar 1. Susunan media dalam bak pengolahan biofiltrasi sistem tanaman kecilberukuran 0,5cm setinggi $20 \mathrm{~cm}$. Pada lapisan pasir ini akan ditanam tumbuhan, yang banyaknya disesuaikan dengan panjang dan lebar akar yang memungkinkan sebagian besar lapisan itu terisi oleh risosfir. Tanaman ini diadaptasikan selama 2 minggu dengan jarak tanam $\pm 10-15 \mathrm{~cm}$.

\subsection{Prosedur Penelitian}

Penelitian ini dilakukan dalam dua tahapan penelitian. Tahap pertama, penyiapan sampel untuk menumbuhkan koloni mikroorganisme pada sistem media tersuspensi sampai fase puncak pertumbuhan mikroorganismenya dan penyiapan tanaman liar Ipomoea crassicaulis, pada petak penyerap (ekosistem lahan basah). Tahap kedua adalah penentuan waktu efektif dan kapasitas biosistem sistem terhadap penurunan rhodamin B, TSS, TDS dan stabilitas $\mathrm{pH}$ dalam air dengan merendamnya selama $0,6,12,18,24,30,36,42$, dan 48 jam.

Data yang diperoleh dalam penelitian ini dianalisis secara deskriptif kuantitatif berupa angka efektivitas dan kapasitas biofiltrasi sistem tanaman serta analisis regresi untuk melihat kurva penurunan konsentrasi rhodamin B terhadap lama waktu perendaman.

Efektivitas pengolahan dari ekosistem buatan dihitung berdasarkan efektivitas proses yang terjadi, yakni penurunan persentase kadar rhodamin b pada saat proses pengolahan. Hasil pengolahan dikatakan cukup efektif apabila persentase efektivitas mencapai di bawah 50\% dan efektif di atas 50\%. Penurunkan kadar limbah rhodamin B ditentukan berdasarkan persamaan berikut (Metcalf dan Eddy, 1991).:

$$
\% \text { Efektivitas }=\frac{(C a-C t)}{C a} \times 100 \%
$$

Kapasitas pengolahan dari ekosistem buatan dalam menurunkan kadar limbah ditentukan berdasarkan persamaan berikut (Parasara, 2015):

$$
\text { Kapasitas }=\frac{(\mathrm{Ca}-\mathrm{Ct})}{\mathrm{V} \cdot \mathrm{t}_{\mathrm{R}}}
$$

Keterangan :

$\mathrm{Ca}=$ konsentrasi rhodamin b awal $(\mathrm{mg} / \mathrm{L})$

$\mathrm{Ct}=$ konsentrasi rhodamin $\mathrm{b}$ akhir $(\mathrm{mg} / \mathrm{L})($ dengan waktu tinggal yang paling efektif)

$\mathrm{V}=$ volume ekosistem buatan $\left(\mathrm{m}^{3}\right)$

$\mathrm{t}_{\mathrm{R}}=$ waktu tinggal $($ jam$)$

\section{HASIL DAN PEMBAHASAN}

\subsection{Pembibitan Sedimen}

Penentuan waktu optimum pembibitan dilakukan melalui data visual, yang pertama melihat adanya perubahan warna pada larutan bibit. Saat awal pembibitan larutan tampak berwarna merah muda pekat kemudian berangsur-angsur warna 
mulai terlihat memudar. Hal ini disebabkan karena aktivitas dan pertambahan populasi mikroba dalam larutan bertambah sehingga mampu mendegradasi zat warna rhodamin yang terdapat pada larutan bibit. Ciri fisik kedua yaitu mulai tercium bau alkohol dari larutan bibit. Menurut Muchtadi, dkk (2010), dalam keadaan anaerob mikroba melakukan metabolisme berupa fermentasi, mikroba yang melakukan fermentasi membutuhkan energi yang umumnya diperoleh dari glukosa, bakteri mengubah glukosa menjadi air, $\mathrm{CO}_{2}$, dan energi (ATP) yang digunakan untuk kegiatan pertumbuhan. Hasil penguraian adalah energi, $\mathrm{CO}_{2}$, air, dan sejumlah asam organik lainnya seperti asam laktat, asam asetat, etanol, serta bahan-bahan organik yang mudah menguap yakni alkohol, ester, dan sebagainya. Terjadinya fermentasi ini dapat menyebabkan perubahan sifat larutan akibat dari pemecahan kandungan bahan tersebut.

Hasil penelitian pendahuluan mendapatkan bahwa, waktu optimal pembibitan adalah pada hari ke 7. Hal ini dibuktikan dengan bahwa bahwa populasi mikroba tertinggi terdapat pada hari ke 7 dengan jumlah bakteri lebih dari 300 koloni sampai pengenceran ke-8.

\subsection{Penentuan Kemampuan Biofiltrasi Sistem Tanaman}

\subsubsection{Efektivitas Biofiltrasi Sistem Tanaman}

a. Efektivitas Penurunan Nilai Rhodamin B Aplikasi biofiltrasi sistem tanaman untuk menurunkan kadar rhodamin B selama 48 jam dan pada jam ke 216 atau hari ke 7 disajikan pada tabel 2 dan gambar 1 . Waktu efektif penurunan diperoleh pada waktu perlakuan ke 30 jam dengan persentase penurunan sebesar $51,07 \%$.

Tabel 1.Kadar rhodamin B pada berbagai waktu berbeda

\begin{tabular}{lcccc}
\hline No & Waktu & $\begin{array}{c}\text { Kadar } \\
\text { rhodamin } \\
\text { B rata-rata } \\
\text { (mg/L) }\end{array}$ & $\begin{array}{c}\text { Penurunan } \\
\text { kadar } \\
\text { rhodamin B } \\
(\mathrm{mg} / \mathrm{L})\end{array}$ & $\begin{array}{c}\text { Efektivitas } \\
\text { penurunan } \\
\text { rhodamin B } \\
(\%)\end{array}$ \\
\hline 1 & (jam) & 0,7934 & - & - \\
2 & 6 & 0,5960 & 0,1974 & 24,88 \\
3 & 12 & 0,5061 & 0,0899 & 36,21 \\
4 & 18 & 0,4860 & 0,0201 & 38,74 \\
5 & 24 & 0,4389 & 0,0471 & 44,68 \\
6 & 30 & 0,3882 & 0,0507 & 51,07 \\
7 & 36 & 0,3511 & 0,0371 & 55,75 \\
8 & 42 & 0,3196 & 0,0315 & 59,72 \\
9 & 48 & 0,2841 & 0,0355 & 64,19 \\
10 & 216 & 0,0944 & 0,1897 & 88,10 \\
\hline
\end{tabular}

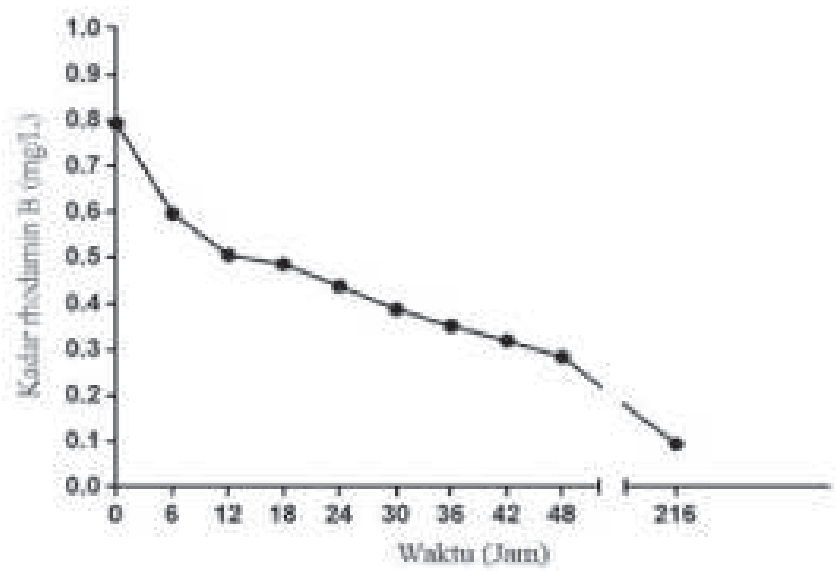

Gambar 2. Grafik penurunan kadar rhodamin b pada selang waktu berbeda

Penurunan kadar rhodamin B pada saat pengolahan disebabkan adanya beberapa proses yang terjadi pada biosistem tersebut. Adanya aktivitas mikroba yang ditambahkan, penyerapan oleh material alam (pasir dan koral), serta penyerapan oleh tanaman Ipomea crassicaulis. Aktivitas mikroba pendegradasi zat warna menyebabkan penurunan pada kadar rhodamin b melalui proses biodegradasi. Berdasarkan hasil uji Laboratorium terdapat 5 isolat bakteri dan 1 yeast yang berhasil diisolasi yaitu bakteri Pseudomonas sp., Shigella sp., Stenotrophomonas sp., Pasteurella sp., Proteus sp., dan yeast (spesies $\mathrm{x}$ ). Mikroba yang digunakan dalam biodegradasi, memproduksi enzim yang memodifikasi polutan toksik dengan mengubah struktur kimia polutan tersebut sehingga menjadi tidak kompleks sehingga kadar toksiknya berkurang, dan menjadi metabolit yang tidak berbahaya (Yanu, 2013).

Proses pengolahan fisika secara adsorpsi dilakukan oleh pasir dan koral, karena pasir dan koral memiliki kandungan silika. Penurunan konsentrasi kadar rhodamin dipengaruhi oleh sifat rhodamin B yang sangat polar. Semakin polar suatu senyawa, maka semakin kuat teradsorpsi. Rhodamin B juga memiliki bobot molekul yang sangat tinggi yang menyebabkan senyawa ini mudah teradsorpsi.

Tumbuhan akan menyerap unsur-unsur hara yang larut dalam air dan tanah melalui akarnya. Tumbuhan dapat menyerap kontaminan sedalam atau sejauh akar tanaman yang dapat tumbuh (Rock dalam Stefhany et al., 2013). Tananan Ipomea crassicaulis yang digunakan pada penelitian ini berumur \pm 3 bulan, terlihat terjadi perubahan tanaman setelah dialiri limbah rhodamin. Tanaman yang awalnya segar dan memiliki daun yang lebat, menjadi layu kekuningan. Hal ini membuktikan bahwa tanaman ikut menyerap rhodamin B sehingga mampu menurunkan kadar rhodamin B dalam air limbah. 


\section{b. Efektivitas Penurunan Nilai TDS (Total Dissolved Solid)}

Analisis TDS dilakukan untuk mengetahui ukuran zat terlarut (baik itu zat organik maupun anorganik) yang terdapat pada larutan. TDS menggambarkan jumlah zat terlarut dalam Part Per Million (PPM) atau sama dengan milligram per Liter $(\mathrm{mg} / \mathrm{L})$.

Penurunan kadar TDS berdasarkan tabel 3 dan gambar 2 terlihat pada waktu awal perlakuan. Persentase penurunan paling efektif diperoleh saat waktu perlakuan ke 36 jam sebesar 47,60\% dengan konsentrasi $661,0226 \mathrm{mg} / \mathrm{L}$. Terjadi kenaikan saat jam ke 18 dari konsentrasi $1006.8286 \mathrm{mg} / \mathrm{L}$ menjadi $1106.7884 \mathrm{mg} / \mathrm{L}$. Kenaikan nilai TDS ini menunjukkan bahwa bahan organik yang berukuran kecil d" 1 ìm belum terdegradasi secara sempurna menjadi gas dan adanya peningkatan biomassa mikroorganisme yang berukuran lebih kecil dari kertas saring ukuran 1 ìm. Faktor lain yang membuat ketidakstabilan pengukuran TDS ada suhu saat pemanasan. Suhu yang digunakan untuk mengeringkan residu sangat penting dan mempengaruhi hasil karena bobot yang hilang akibat bahan organik volatil, air , air kristalisasi, gas yang keluar akibat dekomposisi kimia sebagai bobot akibat oksidasi tergantung suhu dan waktu pemanasan. Nilai TDS berpengaruh terhadap proses pengolahan secara anaerob. Pada proses pengolahan limbah secara anaerob, bahan organik komplek dihidrolisis menjadi organik sederhana (asam organik) oleh mikroba (Seabloom, 2004). Pada fase Methanogenic, asam organik diubah menjadi karbondioksida $\left(\mathrm{CO}_{2}\right)$ dan metan $\left(\mathrm{CH}_{4}\right)$ (Seabloom, 2004). Penurunan nilai TDS pada biofiltrasi sistem tanaman terjadi akibat bahan organik yang terdapat pada sampel air limbah telah dikonversi menjadi gas. Peranan tanaman dalam menurunkan kadar TDS yaitu adalah proses penyerapan unsur hara oleh akar tanaman, pembusukan akar, distribusi debu dari udara ke dalam limbah.

Tabel 2. Kadar TDS (Total Dissolve Solid) pada berbagai waktu berbeda

\begin{tabular}{ccccc}
\hline No & Waktu & $\begin{array}{c}\text { Kadar TDS } \\
\text { rata-rata } \\
(\mathrm{mg} / \mathrm{L})\end{array}$ & $\begin{array}{c}\text { Penurunan } \\
\text { kadar TDS } \\
(\mathrm{mg} / \mathrm{L})\end{array}$ & $\begin{array}{c}\text { Efektivitas } \\
\text { penurunan TDS } \\
(\%)\end{array}$ \\
\hline 1 & 0 & 1261,5537 & - & - \\
2 & 6 & 1103,4377 & 158,116 & 12,53 \\
3 & 12 & 1006,8286 & 96,6091 & 20,19 \\
4 & 18 & 1106,7884 & $-99,9598$ & 12,27 \\
5 & 24 & 1068,3294 & 38,459 & 15,32 \\
6 & 30 & 941,6219 & 126,7075 & 25,36 \\
7 & 36 & 661,0226 & 280,5993 & 47,60 \\
8 & 42 & 461,8431 & 199,1795 & 63,39 \\
9 & 48 & 439,7389 & 22,1042 & 65,14 \\
10 & 216 & 356,3416 & 905,2121 & 71,75 \\
\hline
\end{tabular}

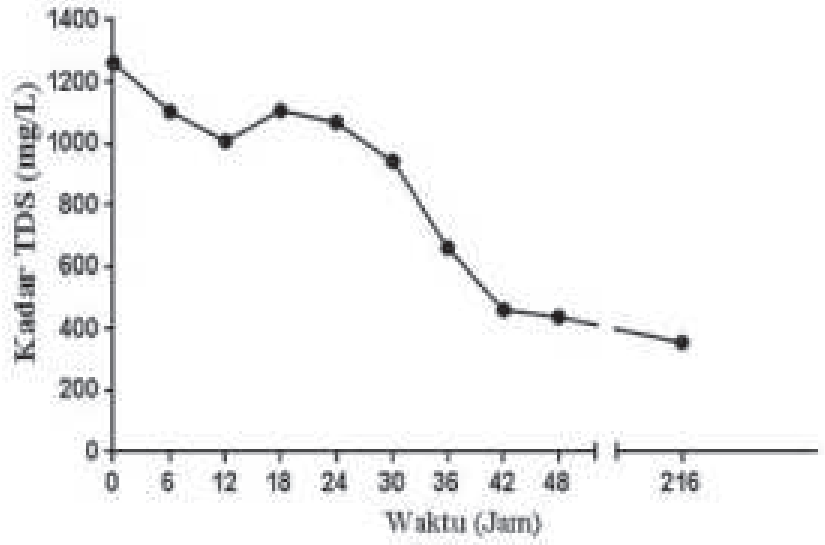

Gambar 3.Grafik penurunan nilai TDS pada berbagai selang waktu berbeda

\section{c. Efektivitas Penurunan Nilai TSS (Total Suspended Solid)}

Zat padat tersuspensi atau TSS adalah semua zat padat atau partikel yang tersuspensi dalam air dan dapat berupa komponen hidup (biotik) seperti fitoplankton, zooplankton, bakteri, fungi, ataupun komponen mati (abiotik) seperti detritus dan partikelpartikel anorganik (pasir, lumpur, dan tanah liat). Zat padat tersuspensi merupakan tempat berlangsungnya reaksireaksi kimia yang heterogen dan berfungsi sebagai bahan pembentuk endapan yang paling awal dan dapat menghalangi kemampuan produksi zat organik di suatu perairan (Tarigan, 2003). Penurunan nilai padatan suspensi total (TSS) dapat dilihat pada tabel 4. dan gambar 3.

Efektivitas terbesar pada penurunan TSS terjadi pada waktu perlakuan ke 36 jam dengan persentase sebesar 50.44 \%.Penurunan nilai TSS dapat disebabkan karena ketersediaan nutrien sebagai bahan makanan bagi bekteri, sehingga aktifitas metabolisme bakteri pun meningkat dan proses degradasi bisa berjalan maksimal. Pada waktu efektif bakteri yang berhasil diisolasi Pseudomonas sp, Pasteurella sp dan Yeast (Spesies x). Menurut penelitian Reza, dkk (2012) Pseudomonas spnmampu menghasilkan biosurfaktan yang dapat menurunkan kadar TSS dari $2.96 \%$ menjadi $1.95 \%$. Padatan yang bisa dilisiskan oleh biosurfaktan adalah padatan organik dengan sifat non-polar, biosurfaktan mengikat padatan organik yang bersifat non-polar sehingga menyatu dengan air yang bersifat polar. Selain bakteri, penurunan TSS melalui fitoremediasi dapat terjadi dengan cara padatan tersuspensi yang berupa bahan organik digunakan oleh tumbuhan sebagai unsur hara yang menunjang pertumbuhan (Deboraet al., 2013). 
Tabel 3. Kadar TSS (Total Suspended Solid) pada berbagai waktu berbeda

\begin{tabular}{lcccc}
\hline No & Waktu & $\begin{array}{c}\text { Kadar TSS } \\
\text { rata-rata } \\
(\mathrm{mg} / \mathrm{L})\end{array}$ & $\begin{array}{c}\text { Penurunan } \\
\text { kadar TSS } \\
(\mathrm{mg} / \mathrm{L})\end{array}$ & $\begin{array}{c}\text { Efektivitas } \\
\text { penurunan TSS } \\
(\%)\end{array}$ \\
\hline 1 & 0 & 40,6687 & - & - \\
2 & 6 & 40,4764 & 0,1923 & 0,47 \\
3 & 12 & 40,3238 & 0,1526 & 0,85 \\
4 & 18 & 32,8426 & 7,4812 & 19,24 \\
5 & 24 & 30,4936 & 2,349 & 25,02 \\
6 & 30 & 28,501 & 1,9926 & 29,92 \\
7 & 36 & 20,1534 & 8,3476 & 50,44 \\
8 & 42 & 20,1234 & 0,03 & 50,52 \\
9 & 48 & 12,1311 & 7,9923 & 70,17 \\
10 & 216 & 10,3399 & 1,7912 & 74,58 \\
\hline
\end{tabular}

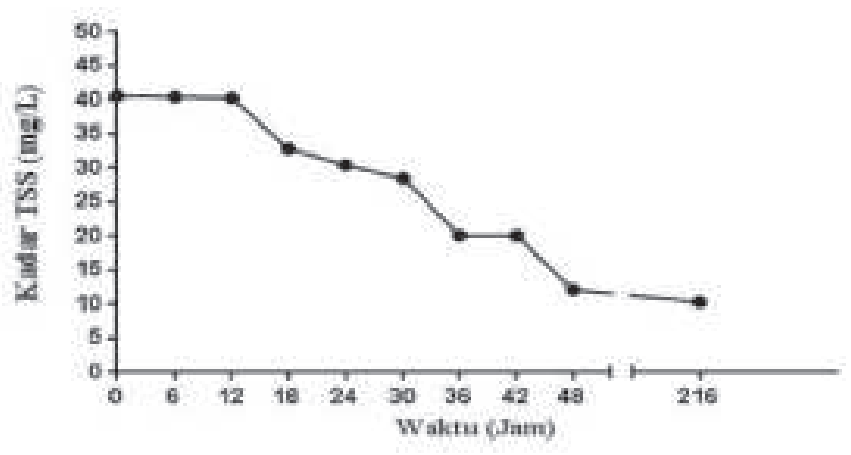

Gambar 4.Grafik penurunan nilai TSS pada selang waktu berbeda

\section{d. Efektivitas Penurunan $\mathbf{p H}$}

Hasil pengukuran $\mathrm{pH}$ selama 48 jam dengan selang waktu 6 jam ditunjukkan pada tabel 4 dan gambar 5. Penurunan $\mathrm{pH}$ terjadi saat waktu ke 12 jam yaitu dari 7,6 menjadi 7,4 namun pada waktu ke 30 jam nilai pH kembali mengalami kenaikan menjadi 7,5. Nilai pH tersebut stabil sampai waktu ke 48 hingga waktu ke 216 jam atau 7 hari setelah hari perlakuan yang direncanakan.

Penurunan nilai pH disebabkan karena perubahan $\mathrm{pH}$ menunjukkan terjadinya proses biodegradasi bahan organik. Aktivitas mikroorganisme pendegradasi memungkinkan terjadi penurunan $\mathrm{pH}$ karena senyawa organik telah diuraikan menjadi asam organik.Bakteri pada waktu perlakuan ke 30 adalah Pseudomonas sp., Stenotrophomonas sp., dan Pasteurella sp. Seperti diketahui Pseudomonas sp. mampu beradaptasi pada $\mathrm{pH}$ yang cenderung basa. Menurut penelitian Sastrawardanaet al., (2008) kondisi pH optimum untuk berlangsungnya perombakan zat warna dengan bakteri Pseudomonas sp. dicapai pada $\mathrm{pH} 7$ 8 dengan efisiensi perombakan $90-95 \%$.
Tabel 4. pH saat pengolahan pada waktu berbeda

\begin{tabular}{lcc}
\hline No & Waktu(jam) & Nilai pH rata-rata \\
\hline 1 & 0 & 7,6 \\
2 & 6 & 7,6 \\
3 & 12 & 7,6 \\
4 & 18 & 7,4 \\
5 & 24 & 7,4 \\
6 & 30 & 7,5 \\
7 & 36 & 7,5 \\
8 & 42 & 7,5 \\
9 & 48 & 7,5 \\
10 & 216 & 7,5 \\
\hline
\end{tabular}

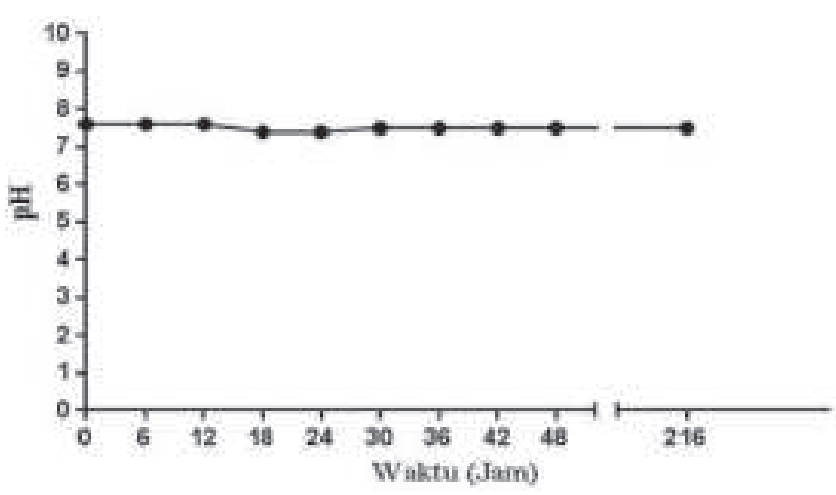

Gambar 5.Grafik kestabilan nilai pH pada selang waktu berbeda

\subsubsection{Kapasitas Biofiltrasi Sistem Tanaman}

Kapasitas pengolahan didefinisikan sebagai suatu kemampuan sistem dalam menurunkan kadar zat pencemar per satuan volume bak (sistem)per satuan waktu (Sugianthi, 2011).Dari hasil perhitungan kapasitas rhodamin B sebesar 0,2256 $\mathrm{mg} / \mathrm{L} / \mathrm{m}^{3} \mathrm{jam}$. Jadi selama waktu tinggal air limbah 30 jam, 0,06 $\mathrm{m}^{3}$ bak pengolahan mampu menurunkan kadar rhodamin B sebanyak 0,2256 mg/ L. Kapasitas nilai TDS 278,0237 mg/L/m ${ }^{3} \mathrm{jam}$, selama waktu tinggal air limbah 36 jam, 0,06 m $\mathrm{m}^{3}$ bak pengolahan mampu menurunkan nilai TDS sebanyak 278,0237 mg/L. Kapasitas kadar TSS mg/ $\mathrm{L} / \mathrm{m}^{3}$ jam, selama waktu tinggal air limbah 36 jam, $0,06 \mathrm{~m}^{3}$ bak pengolahan mampu menurunkan kadar TSS sebanyak 9,4978 mg/L.

\section{SIMPULAN DAN SARAN}

\subsection{Simpulan}

1. Pengolahan menggunakan biofiltrasi sistem tanaman efektif untuk menurunkan kadar rhodamin B dan TSS (di atas 50\%), namun kurang efektif untuk menurunkan kadar TDS (di bawah 50\%). 
2. Kapasitas biofiltrasi sistem tanaman dalam menurunkan kadar rhodamin B $0,256 \mathrm{mg} / \mathrm{L} /$ $\mathrm{m}^{3} \mathrm{jam}$, TDS $278,0237 \mathrm{mg} / \mathrm{L} / \mathrm{m}^{3} \mathrm{jam}$, dan TSS $9,4978 \mathrm{mg} / \mathrm{L} / \mathrm{m}^{3} \mathrm{jam}$.

\subsection{Saran}

1. Penambahan jumlah mikroba agar efektivitas sistem pengolahan dapat berjalan maksimal.

2. Perlu penelitian menggunakan limbah rhodamin B dengan $\mathrm{pH}$ netral sebelum diolah.

3. Penelitian lanjutan mengenai penyebaran rhodamin B pada tanaman, material alam dan bakteri pendegradasi.

\section{DAFTAR PUSTAKA}

Debora, F.S., Mumu,S., dan Kancitrha, P. 2013. Pengolahan Limbah Cair Hotel Aston Braga City Walk dengan Proses Fitoremediasi menggunakan Tumbuhan Eceng Gondok. Jurnal Institut Teknologi Nasional, 1 (2):1-10.

Husin, Amir. 2008. "Pengolahan Limbah Cair Industri Tahu Dengan Biofiltrasi Anaerob Dalam Reaktor Fixed - Bed" (thesis). Medan: Universitas Sumatera Utara.

Kemenperin. 2011. Laju Pertumbuhan Industri Pengolahan Non Migas(Kumulatif). [cited 2014 March 20]. Available from URL :Http:// Www.Kemenperin.Go.Id/Statistik/ Pdb_Growthc.Php.

Laksono, E.W. 2009. Kajian Penggunaan Adsorben Sebagai Alternatif Pengolahan Limbah Zat Pewarna Tekstil. Yogyakarta: Universitas Negeri Yogyakarta.

Metcalf dan Eddy. 1991. Waste WaterEngineering: Treatment DisposalReuse. $3^{\text {rd }}$ Edition. McgrawHill Publishing Company Ltd. New York.

Muchtadi, Tien R., dan Fitriyono A. 2010. Teknologi Proses Pengolahan Pangan. Bandung: Alfabeta.

Parasara, IGNB. 2015. "Pengolahan Air Limbah Domestik Dengan Biosistem Tanaman Basah (Contrusted Wetland) di Bandara Ngurah Rai" (thesis). Denpasar: Universitas Udayana.

Rittmann, B.E., and McCarty, P.L,. 2001.Environmental Biotechnology: Principles and Applications, McGraw Hill International $E d$., New York.
Sari, YD. 2013. Analisis Faktor-Faktor Yang Mempengaruhi Keputusan Konsumen Dalam Membeli Produk Industri Garment. Jurnal Manajement Universitas Udayana, 2(1):86-105.

Sastrawidana, I Dewa, Bibiana, Fauzi, Anas, dan D.A. Santosa. 2008. Pengolahan Limbah Tekstil Sistem Kombinasi Anaerobik-Aerobik Menggunakan Biofilm Bakteri Konsorsium dari Lumpur Limbah Tekstil. Jurnal Ecotrophic, 3 (2): 55-60.

Seabloom, R. B. 2004. University Curriculum Development for Decentralized Wastewater Management: Septic Tanks. Emeritus Professor of Civil and Environmental Engineering Dept. of Civil and Environmental Engineering.Washington: University of Washington.

Stefhany, C.A., Mumu, S., dan Kancitra P,. 2013. Fitoremediasi Phospat dengan Menggunakan Tumbuhan Eceng Gondok (Eichhornia crassipes) pada Limbah Cair Industri Kecil Pencucian Pakaian (Laundry). Jurnal Institut Negeri Nasional, 1 (1): 1-11.

Suwarno, J., Tiarsipeni, Dan Adillah, A. 2003. Penurunan Kadar Fenol Secara Biologis Dalam Reaktor Filter Anaerob Dua Tahap. Majalah Iptek, 14(2) : 65-72.

Sugianthi, R.. 2011. "Pengolahan Air Limbah Pembangkit Listrik PT Indonesia Power dengan Metode Flotasi dan Biofiltrasi Saringan Pasir Tanaman" (skripsi). Jimbaran: Universitas Udayana.

Suyasa, I.W Budiarsa dan Dwijani, Wahyu. 2007. Kemampuan Sistem Saringan Pasir-Tanaman Menurunkan Nilai BOD dan COD Air Tercemar Limbah Pencelupan. Jurnal Ecotrophic., 2(1): 1-7.

Tarigan, M.S dan Edward. 2003. Kandungan Total Zat Padat Tersuspensi (Total Suspended Solid) Di Perairan Raha, Sulawesi Tenggara. Makara Sains.,7(3) : 109-119.

Trestiati, M. 2003. "Analisis Rhodamin B padaMakanan dan Minuman Jajanan Anak SD (StudiKasus : Sekolah Dasar di Kecamatan MargaasihKabupaten Bandung)" (thesis). Bandung: Institut Teknologi Bandung. 